\title{
Sources of Stress among Undergraduate Nursing Students during Clinical Practice: A Malawian Perspective
}

\author{
Gladys Msiska, Martha Kamanga, Evelyn Chilemba, Annie Msosa, Tiwonge Ethel Munkhondya ${ }^{\mathbb{C}}$ \\ Kamuzu College of Nursing, University of Malawi, Lilongwe, Malawi \\ Email: tiwongembeya@kcn.unima.mw
}

How to cite this paper: Msiska, G., Kamanga, M., Chilemba, E., Msosa, A. and Munkhondya, T.E. (2019) Sources of Stress among Undergraduate Nursing Students during Clinical Practice: A Malawian Perspective. Open Journal of Nursing, 9, 1-13. https://doi.org/10.4236/ojn.2019.91001

Received: October 26, 2018

Accepted: January 11, 2019

Published: January 14, 2019

Copyright ( 2019 by author(s) and Scientific Research Publishing Inc. This work is licensed under the Creative Commons Attribution International License (CC BY 4.0). http://creativecommons.org/licenses/by/4.0/

\section{Open Access}

\begin{abstract}
Purpose: The purpose of this study was to explore undergraduate nursing students' perceptions of their clinical learning experience, and the reported findings emerged from narratives of their experience. Design: This was a hermeneutic phenomenological study which took place at a university nursing college in Malawi. Participants for the study were purposively selected from third- and fourth-year undergraduate nursing students and the data were collected through in-depth interviews. A framework developed by modifying Colaizzi's procedural steps guided the phenomenological analysis. Findings: The study reveals factors which cause stress among undergraduate nursing students during their clinical practice. The following themes emerged from the study: lecturer/nurse interaction with students: stress associated with patient care and stress associated with objective structured clinical examination (OSCE). The lecturer is perceived to significantly induce stress, and this is common when the student perceives that the lecturer's interaction is in a "policing" manner. The primary stressors associated with patient care include lack of life-saving medication which sometimes leads to death of a patient, taking care of critically ill patients unsupervised, and fear of contracting infections such as HIV and tuberculosis, and death of a patient. Factors associated with stress during OSCE include use of examiners whom students are not familiar with and the conduct of OSCE in the skills lab which has better resources than the clinical settings where students practice. Conclusions: The study reveals sources of stress during nursing students' clinical practice and its effects on their learning and motivation. Consistent with existing literature, these findings confirm that nursing students experience considerable levels of stress during clinical practice. Recommendations: The study suggests that nursing education can be quite a stressful experience to the learners. It is therefore essential that nurse educators should address the various sources of
\end{abstract}


stress which the study has revealed to enhance students' clinical learning and provide the student nurses with the needed care.

\section{Keywords}

Stress, Clinical Practice, Clinical Learning, Student Nurses, Nursing Education

\section{Introduction}

Nursing is known to be stressful, and there is evidence of the occurrence of stress among undergraduate nursing and midwifery students. Stress among nursing students has been widely investigated in western countries [1], and recently there has been a growing body of research on stress among nursing students conducted in eastern countries. Few studies in the literature have explored stress among African student nurses, and the findings in this paper contribute to such literature. Sources of stress among nursing students are categorised into academic, clinical and personal factors [2]. However, the literature reveals that nursing students experience considerable levels of stress during their clinical practice [3], and the findings of this study report some of the stressors that confront nursing students during their practice. There is evidence that stress affects academic performance and students' well-being [1] [3], and the findings in this study, portray how it hinders students' clinical learning. These findings can assist educators to identify appropriate interventions to prevent or reduce the occurrence of stress. The study, whose findings are reported in this paper, was not intended to explore stress among nursing students, but these findings emerged as the students who participated in the study narrated their clinical practice experience.

\section{Research Design}

The study employed a qualitative research approach, to investigate the social world. According to Blaikie, the social world is the world interpreted and experienced by its members from the "inside" [4]. Student nurses are "insiders" in so far as their own clinical practice experience is concerned, and their narrative accounts provide the "insider view." The study used hermeneutic phenomenology to explore the clinical learning experience of undergraduate nursing students in Malawi. However, a detailed description of the research design is not presented in this paper but can be located in detail in [5] [6].

\subsection{Study Setting and Participants}

The study took place in Malawi at one of the university colleges. Participants for the study were third, and fourth-year undergraduate nursing students who were purposively selected to participate in the study. The sample consisted of 30 par- 
ticipants; this was at a point when data saturation was obtained.

\subsection{Data Collection}

In-depth interviews were used to obtain narrative accounts from the participants regarding their clinical practice experience. The interviews were conversational in nature, and this is consistent with Gadamer who believed that the conversation aims to allow immersion into the subject matter, and this enables the researcher to gain understanding of the phenomena being investigated [7].

\subsection{Data Analysis}

Data analysis was guided by a framework which was developed through modification of Colaizzi's [8] procedural steps for phenomenological analysis. The reasons for the modifications could be located from [5] [6].

\subsection{Ensuring Rigour}

To ensure rigour, four criteria for trustworthiness by Lincoln and Guba [9] which include: credibility, dependability, confirmability, and transferability, were utilised in this study. To ensure credibility of findings, persistent observation, and member checking were used. Persistent observation allows the researcher to identify pertinent issues about the phenomena being investigated and to explore them in detail [9]. This was possible because one of the authors conducted the interviews and was able to identify pertinent issues and to explore them further during subsequent interviews. According to Lincoln and Guba [9], member checking is the most crucial technique of establishing credibility of findings, and this involved validating the findings with the participants from whom data was collected. Additionally, the study findings include excerpts from participants' narratives, and this is aimed at enhancing the credibility of findings as it shows that the study findings are representative of the participants' narratives. Lincoln and Guba [9] recommend that the confirmability audit is the primary technique for establishing confirmability of the study. Clayton and Thorne [10] indicate that a completed reflexive diary provides evidence from which the decision-making trail could be audited, and a diary was maintained throughout the research process for this purpose. There is evidence that there are close links between dependability and confirmability [9]; therefore, the same strategies apply and promote dependability of the study. Transferability has been achieved through the inclusion of enough descriptive data for readers to evaluate the applicability to other settings.

\subsection{Ethical Considerations}

Ethical approval for the study was obtained from the ethics committee at the School of Health in Social Science (University of Edinburgh), and locally in Malawi, from the College of Medicine Research and Ethics Committee (COMREC) of the University of Malawi. Also, permission to conduct the study was sought 
from the head of the institution where the study took place, and verbal and written consent were obtained from individual participants.

\section{Findings}

This study reveals the occurrence of stress among Malawian undergraduate nursing students during their clinical practice. The study participants were senior students, however; they also narrated some of their stressful encounters as novice students. The following themes emerged from the study: lecturer/nurse interactions with students: a source of stress; stress associated with patient care; and stress associated with objective structured clinical examination (OSCE). The findings are therefore presented under these themes.

\subsection{Lecturer/Nurse Interaction with Students: A Source of Stress}

The study reveals that the presence of a lecturer in the clinical setting arouses stress in students. One of the participants said:

It becomes stressful when the supervisor [lecturer] has decided to observe me $[\ldots]$ because somebody is observing you or evaluating you, you tend to make mistakes.

Lecturers' visits for clinical teaching and supervision are quite erratic. Consequently, students feel threatened when they appear in the clinical setting. One of the participants described it this way:

Inmost of the clinical allocations, we don't have much supervision; [...] so when they come [lecturer], [...], it's like they are a threat or a stressor to the students.

Stress commonly occurs when the lecturer interacts with the student in an unfriendly and intimidating manner, and students refer to such impersonal interactions as "policing." The study reveals that nursing students avoid such lecturers. One of the participants said:

Sometimes other clinical supervisors [lecturers] may make learning so hard, in a sense that, for example, you are doing a procedure on a client, the clinical supervisor would come in the sense like policing you. [...] The policing is being done in the sense that you are doing the procedure, and the supervisor comes in, starts asking you questions.

Similarly, another participant said:

The most stressful thing is the supervisors [lecturers] because whenever they come, $[\ldots]$ they don't look at positives you are doing; they only look at the bad things. [...] This may be the reason why when students see the supervisor coming, most of them run away. It is because they don't want to be humiliated.

The study findings reveal the effects of stress on students' performance and 
the excerpt below illustrates this:

Sometimes when lecturers come to the ward you become nervous [...] you don't even know what to do when he asks you what you are doing, you even fail to explain [...]. The approach is different some use approaches like they are "policing" you.

Some of the stressful clinical experiences which nursing students encounter have to do with their relationships with the clinical nurses. One of the participants gave the following account:

You ask the nurse to supervise you, and they will tell you no, I'm busy. Even sometimes other nurses will say how can I teach you when you are the one who is pursuing a degree? [...] and the supervisor [lecturer] does not come regularly. So, it was stressful that sometimes you say should I go to the wards? Just having the demotivation.

Additionally, another participant said:

When I was in first year, we were allocated to [name of hospital \& ward], and there was a poor relationship between the sister-in-charge and third-year students. So, this nurse was projecting her anger on every student. So actually, we didn't learn much [...] this was a very stressful moment for us.

Sometimes students are also stressed when they commence a placement because of what they may have heard "on the grapevine" from their peers. One of the participants had this to say:

I was allocated to [name of ward]. Now the stressor was the ward in charge because I heard rumours from my friends that the in-charge [ward sister] is very difficult. So by just looking at her, it was stressful to me.

Sometimes lecturers, nurses and even doctors shout at students which also arouse stress. One of the participants made the following comment:

When you are being shouted at during a procedure, I feel it's stressful [...], so I feel being shouted at by a lecturer, or maybe nurses or doctors, it's stressful [...], and you are not free to ask questions.

These findings reveal that the presence of a lecturer in the clinical setting arouses stress. Furthermore, unfriendly communications exacerbate the problem making the students to be overly stressed, and they begin to avoid the lecturer. There is also evidence that stressful experiences occur because of poor nurse/student relationships.

\subsection{Stress Associated with Patient Care}

Nursing students in Malawi more common practice in resource-poor clinical settings and the lack of resources is regarded as a major clinical stressor. One of the participants gave the following account: 
I have ever seen several situations in a hospital where even lives are lost because you don't have resources [...] it's so stressful, and when you stand there with your knowledge, your skills, everything, but you can't do anything, and it's so stressful.

Nursing students reported that sometimes they are left unsupervised, and they have to take care of critically ill patients independently. This causes considerable stress, and one of the participants had this to say:

When students go on a clinical allocation, they [nurses] take that as a replacement for shortage of staff, [...] you would see that they are leaving you alone to do nursing work and there are times you don't know what to do, [...] I also look at that as one of the stressful moments.

Similarly, another participant said:

Some nurses think that our presence in the ward is a relief. [...] They will leave critical conditions that they are supposed to take care of $[\ldots]$ which becomes stressful at times.

Fear of contracting HIV and infections like tuberculosis (TB) is one of the sources of stress, and the excerpt below attests to this:

When we were in paeds [paediatric ward], I was putting up a blood transfusion, but that kid was HIV positive, and as I inserted a cannula then that kid pushed me, and blood splashed into my eyes. [...] I didn't go for testing [...] but I went after a week, and the results were negative. But just three days ago [Interview period] I went again, I had stress to say eh, what if I have it, what then, will I continue with my education or not?

Another participant said:

When I was allocated to go to TB ward, the feeling I had was that by the moment I will be leaving the ward I will be infected as well. [...], so that alone stressed me, it was so stressful to work in a TB ward; I would put on a mask every time. Where I don't have any mask, I would hold my breath.

Likewise, another participant said:

When I was in TB Ward for the first time, it was stressful for me [...] I failed even to care for the patients because what I was thinking about is my safety. Am I going to come out safe without having this disease?

Some stressful encounters occur following the death of patients, and several factors lead to stress in such cases. One of the participants described it this way:

The most stressful thing that I can say was something about death. Because I can say when somebody dies it's something that is demotivating to the student because when you are in year one, what it feels like is when you give nursing care, that patient at least has to improve, and when that patient has died, you feel stressed, you start analysing all those things that you did for 
the patient.

Another participant made the following comment:

Sometimes a patient would die soon after you have done something to the client, so eventually, it was difficult to accept that the client has died due to something like a natural death [...] We used to give drugs based on the way they have been prescribed and sometimes clients could die, so it was difficult to continue working, you feel guilty that I have killed a patient.

These findings depict some of the causes of stress during nursing students' clinical practice. The study identifies lack of resources, caring for critically ill patients unsupervised, fear of contracting HIV and other infections like tuberculosis and death of patients as possible stressors.

\subsection{Stress Associated with Objective Structured Clinical Examination (OSCE)}

OSCE is one of the evaluation method used to assess the clinical performance of nursing students, and the study reveals that nursing students perceive it as being quite stressful. One of the participants had this to say:

OSCE is very stressful [...] some lecturers, just reading their faces, you tend to develop fear to say will things go well with me? So during OSCE, you have different lecturers, others you've never been with them in class, but you just find them there [OSCE station], so it is so stressful [...] They give us ten minutes to conduct the procedure and prepare equipment, it is too short for us, so you become stressed, and you tend maybe to miss out whatever you are doing.

Similarly, another participant said:

We fail OSCE not because we don't know, but because we are having lecturers whom we don't know [...], so it's threatening to us.

Students expressed that they find OSCE difficult because their learning in the clinical area substantially involves less than the ideal nursing practice, whereas, during OSCE, lecturers expect them to perform procedures in an ideal way. They cited minimal supervision and support from lecturers, and the lack of resources as being the leading causes of the perceived skills deficit. The following excerpt illustrates this.

Supervision is being done poorly in the wards, but if it comes to OSCE, there are a lot of lecturers and two at one station. However, we tend to wonder; if we go to the wards we don't see them [...] How can they test us on what we have learnt if they were not there to support us? OSCE is stressful because we know when we are in the ward we are alone. We don't do the correct things; we do shortcuts.

The other concern is about having OSCE in the skills laboratory where there 
are adequate material resources compared to the hospital settings where students practice, and also where manikins are used as opposed to real patients. One of the participants had this to say:

Most clinical settings do not have equipment which we are supposed to use when carrying out procedures, but the equipment now appears on OSCE. When I was at the clinical area, I was doing those procedures, but perhaps I was doing shortcuts or using inappropriate equipment [...], so that will affect how I will handle and use the equipment.

Another participant also said:

But all in all, OSCE should be done on real human beings, on patients, especially in the clinical area where the real equipment that we normally use is.

These findings reveal that OSCE is one of the stressful moments that nursing students experience. The main factors causing stress during OSCE are; the use of examiners whom students are not familiar with. Additionally, two examiners assess a student per OSCE station, which also increases the students' stress. The lack of resources in the clinical settings where students practice also leads to stress. It makes students to learn "shortcuts", and this causes them to dread OSCE which requires ideal practice for successful performance.

\section{Discussion}

Students' stress during clinical practice is an issue which nurse educators need to consider seriously due to its potential to hinder student performance and motivation to learn. This is also important due to the dynamic nature of the clinical learning environment (CLE), which arguably, could be said to be inherently stressful. There are some illustrations in literature to this effect. For example, Edgecombe and Bowden [11] used the swamp as an analogy for the CLE. They indicate that for beginning nurses, the CLE initially may seem wet, messy, boggy and threatening. Additionally, literature reveals that sometimes nursing students feel overwhelmed and overcrowded with things and they don't know what to learn from the CLE [12]. Furthermore, Papp, Markkanen and von Bonsdorff [13] revealed that the CLE has multiple stimuli which make it hard for students to identify what is essential for their learning. All these factors clearly illustrate that the CLE is inherently stressful, and the other stress factors prevalent, for example, as revealed in this study worsen the stress which nursing students experience. Whereas literature reveals the prevalence of stress among nursing students, it is argued that students who practice in resource-poor clinical settings, as is the case in Malawi, experience high levels of stress.

This current study reveals that nursing students perceive lecturers to be their main source of stress during their clinical practice. The presence of a lecturer at the patient's bedside as a student is performing a procedure will normally arouse stress. However, the lecturer-student interaction is perceived as being stressful 
when the student does not know the faculty member personally. This indicates that stress is induced where interactions occur in the absence of lecturer-student relationship. This is consistent with Gillespie [14] who revealed that knowing the lecturer has a positive influence on student's trust and ease with the lecturer. This current study reveals another important factor. It reveals that stress during the lecturer/student interaction occurs when the student perceives that the interaction is in a form of "policing". This occurs when the lecturer appears on the scene while the student is performing a procedure, and begins to "fire questions". Students perceive such interaction as intimidating and humiliating, and they avoid such lecturers. This reflects avoidance coping strategies which Chan, So and Fong [15] also revealed in their study. Consistent with Bond [16], the findings in this study confirm the occurrence of shaming practices in clinical nursing education.

Isaacson and Stacy [17] indicate that nursing students are often nervous when interacting with faculty in the clinical area and they perform better in the absence of faculty. Debatably, this ought not to be so. Indeed there is a point at which allowing a student to gain independence is required, but the support of a lecturer is important, more especially, where faculty-supervised practicum [18] is a form of a practice education model in use. Birchenall [19] argued that without facilitation students become aimless in their endeavours to glean anything worthwhile from their practice experience, and this is true even in these contemporary times. A situation where students feel that they work better in the absence of a faculty member should raise concerns. It is argued that "working better" in this sense might mean that students work in a stress-free environment, but it may not mean that they learn better. Nurse Educators are critical in the facilitation of students' learning in the clinical area. They should aim at ensuring the fruitfulness of teaching-learning interactions [20], and their presence should inspire or motivate the students to learn and should not cause them to be overly stressed.

Stress is known to have a potential to impede learning and performance [3], and the findings in this study indicate how this is achieved. For example, the findings reveal that stress is associated with error in performance of nursing procedures, or the student may fail to explain what they are doing, or in extreme cases, they may not know what to do. Yonge, Myrick and Haase [21] posited that stress can stimulate achievement, but if excessive, may incapacitate an individual to a point of impairing cognitive functioning. The reported failure in performance depicted in this study is an indication of impaired cognitive functioning due to stress which the student experiences because of the lecturer's presence. Stress has to do with emotions, and Weiss [22] conclusively demonstrated how emotions and thought are interconnected, which provides an explanation for the impaired cognitive functioning which students in this study demonstrated due to stress. Furthermore, there is evidence that studentsdid not feel free to ask questions because of poor lecturer/student relationships and the resultant stress. This is contrary to what is expected for learning to take place. The creation of a positive learning environment requires the lecturer to develop a climate where 
students feel free to ask questions [23]. The tendency to "run away" or to avoid lecturers for fear of being humiliated implies that students missed potential learning opportunities. All these factors illustrate how stress impedes learning.

Consistent with existing literature [24] [25] [26], this study supports that nursing students perceive OSCE as being stressful, which adversely affects their performance. The study reveals factors which cause stress during OSCE. One of the factors has to do with the fact that some of the examiners were lecturers whom students had had no prior encounter with, and they did not know them personally. This again reflects the importance of knowing in a lecturer-student relationship. More examiners are required because of large cohorts of students, and therefore some are bound to be unfamiliar to students. The aim is to have two examiners per OSCE station so that students' performance will not be determined based on judgments of a single examiner. Watson et al. [27] illustrate the advantage OSCE has, in that it is possible to introduce objectivity by using examiners or observers who do not know the students. However, as this study reveals, this is what students do not like because it causes stress.

The other cause of stress during OSCE is associated with the gross lack of supplies and equipment which is prevalent in most clinical settings in Malawi. Students practise in resource-poor clinical settings, and they claimed that their practice in such settings falls below ideal nursing practice. This caused them to dread OSCE because they felt that they had become accustomed to the "shortcuts," and yet examiners would require them to perform procedures in an ideal manner, and to utilise appropriate equipment. OSCE is conducted in the skills laboratory, and the study reveals that nursing students prefer that it should be done on real patients, and in the clinical area. The students expressed the desire to be assessed under the conditions which are similar to the environment in which they practise.

\section{Recommendations}

The findings in this study reveal factors which arouse stress during students' clinical practice, and the discussion illustrates how stress impedes students' learning. These findings have implications for nursing education, and the following recommendations are proposed to mitigate the various stress factors:

- Lecturers are perceived to be the main source of stress, and stress occurred with poor lecturer-student interactions/relationships. Literature reveals the importance of building connected lecturer/student relationships, where personal knowing is quite critical [14], and the need to support educators to develop relational competence [20] is recommended. Besides, there should be continuing professional development programmes for educators and clinical nursing staff on effective clinical teaching and supervision.

- Al-Zayyat and Al-Gamal (2014) propose workshops on communication skills which are also recommended to improve lecturer-student interaction. Bond [16] argues that competent nursing faculty who are supportive and respectful 
in their relationships with students will ameliorate the stressful environment which is prevalent in the clinical classroom. Nursing faculty, therefore, need to recognise this and ensure that they comport themselves accordingly.

- The study reveals stress associated with patient care. Some of the stressors include taking care of critically ill patients unsupervised, fear of contracting HIV infection and tuberculosis and death of patients. It is therefore recommended that students should be adequately prepared before they can commence their clinical practice. Educators should ensure that students have understood principles of infection prevention to avoid unnecessary stress.

- OSCE is an effective strategy for assessing the clinical performance of nursing students, but nursing students perceive it as being quite stressful. Literature reveals strategies for reducing stress during OSCE which the authors of this paper support and recommend. Administering OSCE formatively as a teaching tool can promote confidence in students and reduce stress [28]. Also, "Mock" OSCEs conducted before the final OSCE are helpful to ease stress (Muldoon et al., 2014).

\section{Conclusion}

The study explored the clinical learning experience of undergraduate nursing students in Malawi, and the findings reflect the stressors which confront students during their clinical practice. Stress is associated with lecture/nurse-student interaction, and stress is mainly induced when the lecturer is unfriendly and communicates in an intimidating and humiliating manner. Stress is also associated with patient care, the stressors being lack of resources, more especially, lack of life-saving drugs which sometimes causes death of patients, taking care of critically ill patients unsupervised, fear of contracting infections like HIV and tuberculosis and death of patients. Finally, stress is also associated with OSCE. There are concerns regarding the administration of OSCE namely, use of examiners whom students are not familiar with, and the conduct of OSCE in the skills lab which has better resources than the clinical settings where students practice. These are the factors which cause stress during OSCE.

\section{Acknowledgements}

The authors are grateful to the nursing students who participated in the study and ably articulated their clinical practice experience and the associated challenges.

\section{Conflicts of Interest}

The authors declare no conflicts of interest regarding the publication of this paper.

\section{References}

[1] Burnard, P., Binti, H.T., Rahim, H.A., Hayes, D. and Edwards, D. (2007) A Descrip- 
tive Study of Bruneian Student Nurses' Perceptions of Stress. Nurse Education Today, 27, 808-818. https://doi.org/10.1016/j.nedt.2006.11.002

[2] Gibbons, C., Dempster, M. and Moutray, M. (2008) Stress and Eustress in Nursing Students. Journal of Advanced Nursing, 61, 282-290.

https://doi.org/10.1111/j.1365-2648.2007.04497.x

[3] Jimenez, C., Navia-Osorio, P.M. and Diaz, C.V. (2010) Stress and Health in Novice and Experienced Nursing Students. Journal of Advanced Nursing, 66, 442-455. https://doi.org/10.1111/j.1365-2648.2009.05183.x

[4] Blaikie, N.W.H. (2009) Designing Social Research: The Logic of Anticipation. 2nd Edition, Polity, Cambridge.

[5] Msiska, G., Smith, P. and Fawcett, T. and Munkhondya, T.M. (2015) Where Is the Grade Coming from? Problems and Challenges in Evaluating the Clinical Performance of Nursing Students. Open Journal of Nursing, 5, 470-481.

[6] Msiska, G., Smith, P. and Fawcett, T. (2014) Emotive Responses to Ethical Challenges in Caring: A Malawian Perspective. Nursing Ethics, 21, 97-107.

https://doi.org/10.1177/0969733013487191

[7] Gadamer, H.-G. (2004) Truth and Method. Translation Revised by Joel Weinsheimer and Donald G. Marshall.

[8] Colaizzi, P.F. (1978) Psychological Research as the Phenomenologist Views It. In: Valle, R.S. and Mark, K., Eds., Existential Phenomenological Alternatives for Psychology, Oxford University Press, New York, 48-71.

[9] Lincoln, Y.S. and Guba, E.G. (1985) Naturalistic Inquiry. Sage, Beverly Hills, CA.

[10] Clayton, A.M. and Thorne, T. (2000) Diary Data Enhancing Rigour: Analysis Framework and Verification Tool. Journal of Advanced Nursing, 32, 1514-1521. https://doi.org/10.1046/j.1365-2648.2000.01609.x

[11] Edgecombe, K. and Bowden, M. (2009) The Ongoing Search for Best Practice in Clinical Teaching and Learning: A Model of Nursing Students' Evolution to Proficient Novice Registered Nurses. Nurse Education in Practice, 9, 91-101. https://doi.org/10.1016/j.nepr.2008.10.006

[12] Brown, L., Herd, K., Humphries, G. and Paton, M. (2005) The Role of the Lecturer in Practice Placements: What Do Students Think? Nurse Education in Practice, 5, 84-90. https://doi.org/10.1016/j.nepr.2004.03.006

[13] Papp, I., Markkanen, M. and Von Bonsdorff, M. (2003) Clinical Environment as a Learning Environment: Student Nurses' Perceptions Concerning Clinical Learning Experiences. Nurse Education Today, 23, 262-268. https://doi.org/10.1016/S0260-6917(02)00185-5

[14] Gillespie, M. (2002) Student-Teacher Connection in Clinical Nursing Education. Journal of Advanced Nursing, 37, 566-576. https://doi.org/10.1046/j.1365-2648.2002.02131.x

[15] Chan, C.K.L., So, W.K.W. and Fong, D.Y.T. (2009) Hong Kong Baccalaureate Nursing Students' Stress and Their Coping Strategies in Clinical Practice. Journal of Professional Nursing, 25, 307-313. https://doi.org/10.1016/j.profnurs.2009.01.018

[16] Bond, M. (2009) Exposing Shame and Its Effect on Clinical Nursing Education. Journal of Nursing Education, 48, 132-140. https://doi.org/10.3928/01484834-20090301-02

[17] Isaacson, J.J. and Stacy, A.S. (2009) Rubrics for Clinical Evaluation: Objectifying the Subjective Experience. Nurse Education in Practice, 9, 134-140.

https://doi.org/10.1016/j.nepr.2008.10.015 
[18] Budgen, C. and Gamroth, L. (2008) An Overview of Practice Education Models. Nurse Education Today, 28, 273-283. https://doi.org/10.1016/j.nedt.2007.05.005

[19] Birchenall, P. (2001) Educational Facilitation: A Developing Role. Nurse Education Today, 21, 249. https://doi.org/10.1054/nedt.2001.0597

[20] Gillespie, M. (2005) Student-Teacher Connection: A Place of Possibility. Journal of Advanced Nursing, 52, 211-219. https://doi.org/10.1111/j.1365-2648.2005.03581.x

[21] Yonge, O., Myrick, F. and Haase, M. (2002) Student Nurse Stress in the Preceptorship Experience. Nurse Educator, 27, 84-88. https://doi.org/10.1097/00006223-200203000-00012

[22] Weiss, R.P.J.T. (2000) Brain Based Learning. Development, 54, 21.

[23] Nicholl, H.M. and Tracey, C.A.B. (2007) Questioning: A Tool in the Nurse Educator's Kit. Nurse Education in Practice, 7, 285-292. https://doi.org/10.1016/j.nepr.2006.09.002

[24] Rushforth, H.E. (2007) Objective Structured Clinical Examination (OSCE): Review of Literature and Implications for Nursing Education. Nurse Education Today, 27, 481-490. https://doi.org/10.1016/j.nedt.2006.08.009

[25] Nulty, D.D., Mitchell, M.L., Jeffrey, C.A., Henderson, A. and Groves, M. (2011) Best Practice Guidelines for Use of OSCEs: Maximising Value for Student Learning. Nurse Education Today, 31, 145-151. https://doi.org/10.1016/j.nedt.2010.05.006

[26] Muldoon, O.T. and Reilly, J. (2003) Career Choice in Nursing Students: Gendered Constructs as Psychological Barriers. Journal of Advanced Nursing, 43, 93-100. https://doi.org/10.1046/j.1365-2648.2003.02676.x

[27] Watson, R., Stimpson, A., Topping, A. and Porock, D. (2002) Clinical Competence Assessment in Nursing: A Systematic Review of the Literature. Journal of Advanced Nursing, 39, 421-431. https://doi.org/10.1046/j.1365-2648.2002.02307.x

[28] Alinier, G. (2003) Nursing Students' and Lecturers' Perspectives of Objective Structured Clinical Examination Incorporating Simulation. Nurse Education Today, 23, 419-426. https://doi.org/10.1016/S0260-6917(03)00044-3 